\title{
O amanhã que nunca veio: Mulheres e musicalidade na literatura intermidiática de Haruki Murakami
}

Thainara Amorim ${ }^{1}$

RESUMO: A presente resenha tem o intuito de discutir o título South of the Border, West of the Sun (1998), do escritor japonês Haruki Murakami (que será lançado nas livrarias brasileiras pela Alfaguara, selo da Companhia das Letras), apontando suas semelhanças com a obra Norwegian Wood (2011) do mesmo autor. Além disso, a análise busca refletir sobre a representação feminina no cânone murakamiano.

Palavras-chave: South of the Border, West of the Sun. Norwegian Wood. Haruki Murakami. Representação feminina. Literatura japonesa contemporânea.

Após a publicação do primeiro livro que fugia às suas veias fantásticas, Norwegian Wood (2011), o escritor japonês Haruki Murakami decide repetir o desafio no controverso South of the border, West of the Sun (1998). O livro que polarizou a crítica internacional por seu cunho mais realista, seu enredo modesto e sua falta de gatos falantes, é inédito no Brasil no momento em que escrevo ${ }^{2}$, mas será em breve publicado pela Alfaguara, selo da Companhia das Letras, sob o título Sul da Fronteira, Oeste do Sol.

A segunda empreitada de Murakami no gênero realístico foi, de fato, menos ambiciosa que a primeira. O romance é curto e narra a vida do pequeno empresário Hajime, casado com a filha de um banqueiro de caráter duvidoso, mas que não consegue superar o seu primeiro amor, Shimamoto. O plot principal, que inicialmente carrega um tom extremamente novelesco, é um pouco mais complexo do que essa simples sinopse que ofereço. O livro, que está entre os mais populares trabalhos do autor ao redor do mundo, estranhamente demorou quase três décadas para ser traduzido em terras brasilis, onde o romancista faz considerável sucesso. No entanto, as quase 200 páginas primeiro publicadas em 1992, exemplificam de maneira notória, algumas das características mais

\footnotetext{
${ }^{1}$ Graduanda em Comunicação Social pela Universidade Federal de Pernambuco - Centro Acadêmico do Agreste. E-mail: thainara.amorim.37@gmail.com.

${ }^{2}$ A tradução da Alfaguara foi distribuída apenas para os assinantes de julho de 2020 do clube de assinatura de livros TAG.
} 


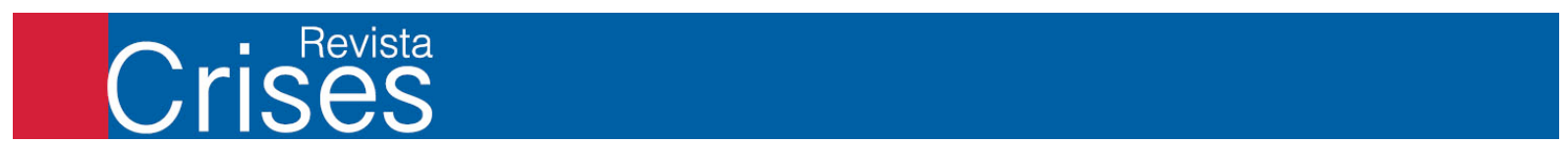

conhecidas do fenômeno literário japonês.

South of the border, West of the Sun é, essencialmente, um livro sobre a morte em suas variadas formas.

Personagem comum no cânone murakamiano, a morte circula o protagonista em todas as fases de sua vida. Desde sua infância solitária e ansiosa por completude aos seus obscuros 37 anos, Hajime jamais desfaz-se do medo e, na mesma medida, da obsessão pelo incógnito. Similarmente ao conto Os mortos (2016) do escritor dublinense James Joyce, a patrulha infindável da morte é a metáfora da angústia que paralisa os personagens em face de um contexto histórico e cultural indefinido e nebuloso.

Nascido no primeiro mês do primeiro ano da segunda metade do século $X X$, o protagonista participa da inquietação de uma geração que nasceu em um momento de transição na sociedade japonesa pós-guerra. Juntamente com a culpa de não ter vivenciado os anos mais difíceis do país, a geração do final dos anos 60 e início dos anos 70 , vive na constante expectativa da concretização das sonoras demandas do movimento estudantil que vão gradativamente se tornando mais silenciosas. Hajime, logo, sofre triplamente com o remorso de desfrutar a vida que, nos seus anos mais jovens, repudiava,

Our generation was the first to yell out a resounding 'No!' to the logic of late capitalism, which had devoured any remaining postwar ideals. It was like the outbreak of a fever just as the country stood at a crucial turning point. And here I was, myself swallowed up in the very same capitalist logic, savoring Schubert's Winterreise as I lounged in my BMW (...) (MURAKAMI, 1998, I. 697). ${ }^{3}$

Para citar a canção que dá nome à obra, os personagens esperam um amanhã que nunca veio ('Cause our tomorrow never came). ${ }^{4}$

A paixão de Murakami pela música transborda em "South of the Border, West of the sun". Com ela, o autor desenvolve uma atmosfera ora idílica, ora fatídica ao redor dos protagonistas. E ainda propõe ao romance um ar biográfico: Hajime, frustrado com o emprego de editor de livros didáticos, proporcionado por seu diploma em literatura

\footnotetext{
${ }^{3}$ Em português: "Nossa geração foi a primeira a bradar um ressonante "Não!" à lógica do capitalismo tardio, que havia devorado todos os ideais remanescentes do pós-guerra. Foi como o início de uma febre no momento em que o país passava por uma virada crucial. E aqui estava eu, engolido pela mesma lógica capitalista, saboreando o Winterreise de Schubert enquanto relaxava na minha BMW." (tradução nossa).

${ }^{4}$ Trecho da música "South of the Border (Down Mexico Way)", composta em 1939 por Jimmy Kennedy e Michael Carr.
} 


\section{Crisevista

japonesa, aceita uma oferta do pai de sua esposa e abre dois bares de jazz que rapidamente se tornam bastante rentáveis. Paralelamente, após sua graduação acadêmica, Murakami também foi proprietário de bares de jazz com sua esposa. Mas para não arriscar perder-me em especulações infrutíferas, abandono por aí as associações entre o criador e a criação.

A trilha sonora que embala as reminiscências melancólicas de Hajime varia, pois, de Bing Crosby à Edvard Grieg. Porém tal intermidialidade óbvia no romance, não se limita apenas à soltas referências dos discos preferidos do protagonista, pois que a música se entrelaça também aos dilemas do herói. "Star-crossed Lovers", presente no álbum "Such Sweet Thunder" (1957) do pianista e compositor Duke Wellington, foi escrita em tributo ao mais célebre casal de Shakespeare e, portanto, representa perfeitamente o amor mal-fadado entre Shimamoto e Hajime.

O diálogo entre as letras e a música parece-me, então, fecundo no trabalho do rock-star literário: seu maior sucesso de vendas, Norwegian Wood, empresta o título da famosa canção dos Beatles. Já o título do seu próximo romance, Dance, Dance, Dance (2015), deriva de uma música da banda de rock americana The Beach Boys. Curiosamente, Haruki Murakami era indicado como favorito ao Nobel da Literatura de 2016, para o qual a escritora brasileira Lygia Fagundes Telles também era candidata, mas perdeu o prêmio para um músico - Bob Dylan, que está presente igualmente no repertório do autor. ${ }^{5}$

Não obstante sua notável reputação e, embora admirado pela poetisa e cantora punk feminista Patti Smith, não é incomum que Murakami seja criticado negativamente pela representação feminina caricatural em seus romances. Confesso que, como leitora de Jane Austen e Virginia Woolf, essa característica da escrita do best-seller japonês, realmente me incomodou. A partir da leitura de South of the Border, West of the Sun, pude elencar três arquétipos femininos que são facilmente observados em Norwegian Wood - assim como em outras obras do autor - , mas que no primeiro são, um tanto,

\footnotetext{
${ }^{5}$ Entre os indicados ao Nobel da Literatura desde 2011, Murakami foi o autor mais cotado para ganhar pela empresa de apostas britânica Ladbrokes com probabilidade de 4/1 em 2016. Seguido pelo poeta sírio Adonis, com 6/1, e pelo popular romancista americano Philip Roth, com 7/1. Apesar da quase certeza da vitória do favorito japonês nos grandes portais de comunicação americanos, Bob Dylan levou o prêmio, o que causou uma notável comoção na imprensa mundial. Ler mais em: https://www.theguardian.com/books/2016/oct/13/bob-dylan-wins-2016-nobel-prize-in-literature. Acesso em: 02 abr. 2021.
} 


\section{Crisevista

mais marcados.

Ambos os livros são significativamente similares: Em Norwegian Wood, o protagonista Toru Watanabe tem uma vida acadêmica frustrante na turbulenta Tóquio do final dos anos 60 e, para fugir do fluxo enfadonho de seus dias, retira-se numa bucólica pousada para pessoas com transtornos mentais, onde vive a misteriosa Naoko, sua grande obsessão e ex-namorada de seu amigo Kizuki, que suicidou-se na adolescência. Ao voltar para casa, porém, encontra frequentemente a ousada Midori, com quem Watanabe decide ficar depois que Naoko, assim como o seu falecido namorado, se suicida. Já em South of the Border, West of the Sun, Hajime, também frustrado com o vazio de seus dias, recorre à sua fixação de infância, a esquiva Shimamoto, mas ao retornar para casa, refugia-se em Yukiko, sua esposa, e, depois do desaparecimento de Shimamoto, decide se empenhar no relacionamento com ela. É evidente, portanto, a semelhança entre os lugares-comuns de gênero delegados às personagens mulheres nas duas obras.

O principal, ao meu ver, é o arquétipo das mulheres etéreas e misteriosas com quem os protagonistas se relacionam num nível mais psicológico - quase místico - e que saem de suas vidas de maneira tão intrigante como entraram. Essas personagens enigmáticas aparentam ter o único intuito de revelar aos protagonistas algo do mundo e que os modificará para sempre. Tal qual as mulheres de Poe, esses seres deslumbrantes, que pertencem à elevada aura da noite, estão no livro para desaparecer ou morrer. Em Norwegian Wood, Naoko e em South of the Border, West of the Sun, Shimamoto. Para parafrasear o mestre da literatura gótica americana, não existe mais poético tópico do que a morte de uma bela mulher ${ }^{6}$. Murakami deve concordar.

Outro estereótipo feminino comum que figura em South of the Border, West of the Sun, é a progênie de Lilith: mulheres que não deixam escolha aos protagonistas a não ser se tornarem imorais e que os levam a cometer pecados que sem a influência dessas "ninfas" não cometeriam. A personagem que se encaixa completamente nessa espécie demoníaca de mulher é a prima mais velha da primeira namorada de Hajime. Mais experiente que o garoto de 17 anos, a mulher que seduz e rouba não somente a

\footnotetext{
6 "The death then of a beautiful woman is unquestionably the most poetical topic in the world." Trecho do ensaio "The Philosophy of Composition" de 1846. Disponível em:

https://www.poetryfoundation.org/articles/69390/the-philosophy-of-composition. Acesso em: 13 marc. 2021.
} 


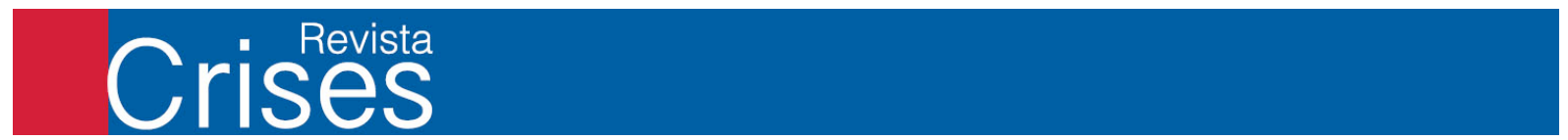

virgindade como a inocência do namorado de sua prima mais próxima, não tem sequer nome, mas carrega uma importância central no romance. Após o ato inescrupuloso praticado por Hajime e que deixa marcas indeléveis na sua ex-namorada, o protagonista perde algo que, até então, achava essencial para a sua existência e, durante o resto da narrativa, ele tenta, sem qualquer sucesso, preencher esse vazio indecifrável, "No matter where I go, I still end up me. What's missing never changes. The scenery may change, but l'm still the same old incomplete person. The same missing elements torture me with a hunger that I can never satisfy." (MURAKAMI, 1998, I. 2058). ${ }^{7}$

A personagem que, com algumas diferenças, poderia ser considerada a exemplar desse tipo em Norwegian Wood é, aparentemente, menos periférica que a prima vil do romance anterior e, inesperadamente, mais intrigante. Midori, ex-estudante de uma escola conservadora para moças, embarca na universidade com muitas ideias de extravasar sua sexualidade reprimida e sua cobaia é Watanabe. A personagem, que tem suas fantasias desprezadas por seu namorado dos tempos de escola, vê no protagonista a oportunidade de se liberar, ainda que ele esteja completamente obcecado por Naoko e resista às suas insinuações suplicantes. llustro com a seguinte passagem, que parece ser tirada de um romance erótico de banca:

- Sabe, Toru, eu não quero que você me ache depravada, insatisfeita ou provocante. É só que tenho muito interesse e quero saber mais sobre esse assunto. Cresci cercada apenas por meninas no colégio de moças. Desejo muito saber o que os homens pensam e como funciona seu corpo. E não nos suplementos da revista feminina, mas num estudo de caso.

— Estudo de caso? - murmurei desesperado.

- Mas se eu sinto vontade de saber ou fazer coisas, meu namorado se irrita. Me chama de depravada. Diz que sou doida varrida. Nunca me deixou fazer sexo oral com ele. Por isso quero muito pesquisar sobre isso (MURAKAMI, 2011, I. 3932).

No entanto, se a personagem mal-explorada que atenta contra a virtude de Hajime assemelha-se à famosa vilã dos romances vitorianos, the mad woman in the attic ${ }^{8}$ e, por conseguinte, é condenada a um fim trágico, Midori não é tão artificial quanto sugere o diálogo anterior. Conquanto a maior parte de suas aparições no livro se limitem à sua

\footnotetext{
${ }^{7}$ Em português: "Não importa aonde eu vá, eu ainda acabo eu mesmo. O que está faltando nunca muda. O cenário pode mudar, mas ainda sou a mesma velha pessoa incompleta. Os mesmos elementos ausentes me torturam com uma fome que nunca poderei satisfazer." (tradução nossa).

${ }^{8}$ Termo cunhado por Sandra Gilbert e Susan Gubar em seu livro The Madwoman in the Attic: The Woman Writer and the Nineteenth-century Literacy Imagination publicado em 1979.
} 


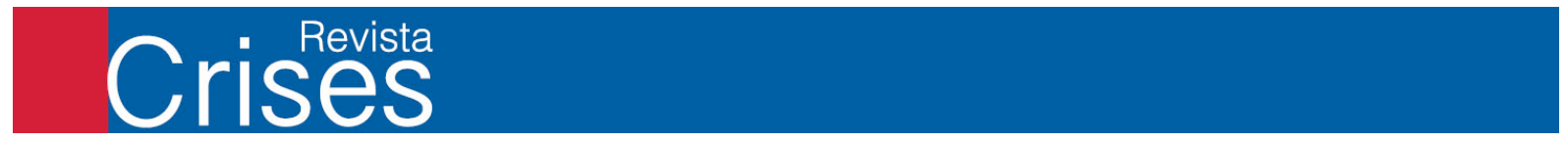

esquisita verborragia sexual, Midori oferece algumas das reflexões filosóficas mais interessantes de Norwegian Wood. Bem como Hajime, a garota também se frustra com o esvaziamento de sentido da grande revolução que os seus colegas universitários a prometem, mas que, na prática, falha em sua fundamentação primeira, "Que revolução é essa que mostra ao povo palavras de significado desconhecido?" (MURAKAMI, 2001, I. 4010).

Além disso, com o passar do romance, o leitor percebe que quem realmente põe em riscos os valores de Watanabe é seu amigo Nagasawa (estudante de diplomacia na Universidade de Tóquio, que se aproxima do protagonista pelos gostos literários em comum), uma espécie de Hajime incorrigível. O amigo bukowskiano do protagonista de Norwegian Wood, tal qual o ilustre Quincas Borbas de Machado de Assis, parece ter sido um personagem irresistível demais para não ser retomado pelo autor. As semelhanças são gritantes: assim como Hajime, Nagasawa também acredita ter um "senso especial" para achar "mulheres especiais", mas algum defeito de caráter o impede de não magoálas irreversivelmente e, no caminho, magoar-se, "É como se dentro de mim existisse uma espécie de sede que exigisse isso de mim para ser aplacada. (...) Eu sou o tipo de homem que vive pressionado por essa sede e não há como tirá-la de mim." (MURAKAMI, 2011, I. 4665). A vítima fatal do descompromisso emocional de Nagasawa é sua namorada de universidade, Hatsumi, que se suicida alguns anos depois do problemático romance. Em South of the Border, West of the Sun, contudo, Hajime encontra uma parceira mais persistente que a namorada de Nagasawa.

Fica impossível de ignorar, consequentemente, a fixação de Murakami por "matar" as mulheres de suas estórias. Assim como na obra de Poe, as personagens femininas parecem servir unicamente para o crescimento e desenvolvimento dos seus protagonistas masculinos e, depois de completarem seu fim, não têm outra saída a não ser sumir ou morrer. Nas palavras do pesquisador Floyd Stovall (1925), as mulheres tão frequentes nos contos e poemas de Poe, em sua prosa, carecem de substância narrativa, são apenas mecanismos para encaminhar o enredo das estórias. Mas nos poemas, elas tomam uma importância poética similar às mulheres de Murakami, são figuras magníficas e quase musicais que, por um curto período, emprestam sua beleza cabalística aos protagonistas. Tal qual as célebres Berenice, Ligeia e Eleonora, do aclamado contista 


\section{Crisevista

americano, Naoko, Hatsumi e Shimamoto representam para Watanabe e Hajime não mais que ideias, que, quando esgotadas, esvaem-se ou perdem forma.

Chegamos, por fim, à última categoria de mulheres narrada por Murakami, as harmonizadoras. São elas que caracterizam o estereótipo do "Anjo do Lar" descrito por Virginia Woolf (2018) em seu texto para a Sociedade de Auxílio às mulheres em 1931, moças que não devem nunca ter opinião própria e que, acima de tudo, são puras, "elas precisam agradar, precisam conciliar, precisam - falando sem rodeios - mentir." (p.13). Tais "boas mulheres" servem de refúgio para os protagonistas e eles as aspiram na tentativa de se reconverterem em "bons homens". Em Norwegian Wood, Hatsumi e em South of the Border, West of the Sun, Yukiko. Ambas provocam a esperança de um sonho adormecido no paraíso perdido da infância dos protagonistas. São, sobretudo, mulheres que Watanabe e Hajime querem salvar para salvar-sem a si próprios.

Recorro novamente à música, que no romance em exame, é mais do que um artifício poético secundário, mas uma forma de interpretação da realidade. Sem muitas explicações, embora tenha ciência das traições de Hajime e de seu amor por Shimamoto, Yukiko ainda deseja continuar ao seu lado. Nada mais simbólico, então, que o trecho da canção "As Time Goes By" (1931), parte da soundtrack do filme "Casablanca" (1942), e que substitui a costumeira faixa tocada pelo pianista do bar como cortesia ao proprietário, "Star-Crossed Lovers", quando esta já não faz sentido: "Woman needs man, and man must have his mate/ That no one can deny".

O realismo pós-moderno de Murakami, todavia carregue fantasmas sexistas clássicos, também apresenta algumas personagens que se distanciam dos arquétipos anteriormente citados. Particularmente, dentre essas personagens "desviantes", a que mais me chamou atenção foi Izumi de South of the Border, West of the Sun. Ainda que tenha ares da Pamela de Samuel Richardson, ou mesmo da Annabel Lee de Poe, dois estereótipos femininos recorrentes na literatura, a namorada traída por Hajime é mais do que um constante lembrete do pior no personagem, é uma alegoria da inconsistência aflitiva da vida.

Izumi evade-se do protagonista em consequência do término nada amistoso do relacionamento entre os dois, mas permanece sofridamente na sua memória. Vinte anos depois, já no final do livro, perturbado pelo absoluto sumiço de Shimamoto, Hajime 


\section{Crisevista

experiencia um encontro quase sobrenatural com Izumi em um táxi no centro de Tóquio. Ao aproximar-se da antiga namorada, percebe que a inocente garota que amava em sua tenra adolescência, também já não existe,

Like a room from which every last stick of furniture had been taken, anything you could possibly call an expression had been removed, leaving nothing behind. Not a trace of feeling grazed her face; it was like the bottom of a deep ocean, silent and dead. And with that utterly expressionless face, she was staring at me. (MURAKAMI, 1998, I. 2002). ${ }^{9}$

Contemplando o vazio de seus olhos, Hajime depara-se com o vazio do mundo, o que confirma a epifania central do romance, "Whatever form can disappear in an instant." (I. 2027). Assim, o que sobra de uma experiência que não deixa rastros concretos? $A$ personagem morta em si mesma representa o melhor do experimentalismo de Murakami, a temível incerteza do que consideramos certo. Izumi ensaia também o corvo de Poe, uma sombra insólita que retorna como um espectro da virtude infantil de Hajime, que busca sua natureza perdida desesperadamente e para quem os mortos olhos de Izumi respondem: "Nevermore!"11

Nesse sentido, outro fato curioso é válido de ser mencionado: a versão de "South of the border (Down Mexico Way)" adorada por Hajime e Shimamoto, nunca foi realmente gravada por Nat King Cole. O leitor poderia então supor, se o próprio Murakami não acabasse de certa forma sugerindo, que Shimamoto é apenas um delírio do protagonista.

Tal foi o meu maior incômodo na leitura de South of the Border, West of the Sun. Não temos o direito de investigar os vestígios do onírico na simplicidade de sua escrita, somos quase sempre guiados pela mão, ao invés de desafiados. Esse aspecto excessivamente explicativo é, na verdade, algo que me desagrada na maioria dos romances de Murakami que li. A despeito de sua vasta experiência no realismo mágico, o autor, com suas tediosas explanações, falha em nos suspender da sobriedade do mundo, efeito primordial para que reflitamos a experiência humana a partir do fantástico. A leitura do romance, portanto, não deixa muito para ser mastigado e nos dá a primeira impressão

\footnotetext{
${ }^{9} \mathrm{Em}$ português: Como um quarto do qual todos os móveis foram retirados, qualquer coisa que você pudesse chamar de expressão foi removida, não deixando nada para trás. Nenhum traço de sentimento tocou seu rosto; era como o fundo de um oceano profundo, silencioso e morto. E com aquele rosto totalmente inexpressivo, ela me encarava." (tradução nossa).

${ }^{10}$ Em português: "Tudo aquilo que possui forma, pode desaparecer em um instante." (tradução nossa).

${ }^{11}$ Refrão do poema The Raven (1845) de Edgar Allan Poe.
} 


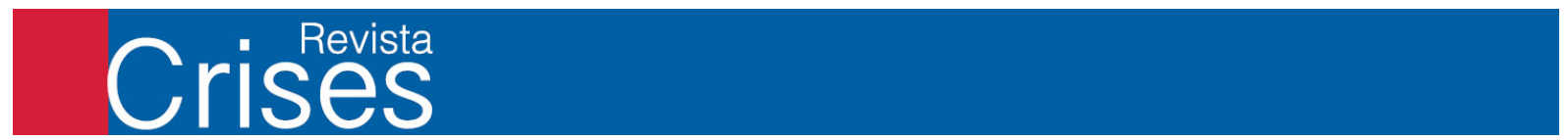

de que não apenas a estória, mas todas as suas possibilidades interpretativas, se esgotam com o virar da última página. Repito: se Murakami nos dissesse menos, ele nos diria mais.

Talvez, o efeito que procuro nos seus romances seja melhor fomentado nos seus menores textos. Em "Queimando celeiros", conto inserido na antologia O Elefante Desaparece (publicada pela Alfaguara em 2018), Murakami bebe de uma de suas maiores inspirações literárias, William Faulkner, para criar uma narrativa atmosférica, instigante e sombria que surpreende o leitor e alcança um mérito poético equiparável ao de O grande Gatsby (2011) de Fitzgerald. Dentro da mesma antologia, a novela "Sono", também é engenhosa na sua fabulação da humanidade. Logo, creio que Murakami é, sobretudo, um bom leitor, mas raramente consegue emparelhar-se ao maravilhoso índice de suas referências.

Finalizo essa resenha com a seguinte consideração: À exceção dos gatos falantes ou não - South of the Border, West of the Sun atende à todos os clichês murakamianos: a perda da inocência, a busca pela identidade, a frustração com a insignificância da própria existência, os discos de jazz e música clássica, as mulheres indecentes e as misteriosas - que sempre desaparecem ou morrem - e os protagonistas masculinos ligeiramente enfadonhos e extremamente desinteressantes. $E$ volto, pois, a minha primeira comparação: Entre as lamentações intermináveis de Hajime e a ingenuidade romântica de Watanabe, prefiro a última.

\section{REFERÊNCIAS}

AUNTRY, Gene. South of the Border (Down Mexico Way). Chicago: Conqueror, 1939. Disponível em: https://open.spotify.com/track/1imCf2NiUOdAZkmceMMCbQ? si=2dcb9cc2c6ce416b. Acesso em: 14, mar. 2021.

BOB DYLAN WINS NOBEL PRIZE IN LITERATURE. The Guardian. Disponível em: https://www.theguardian.com/books/2016/oct/13/bob-dylan-wins-2016-nobel-prize-inliterature. Acesso em: 02, abr. 2021.

MURAKAMI, Haruki. Norwegian Wood. Rio de Janeiro: Objetiva, 2011. 1998.

South of the Border, West of the Sun. Nova lorque: Vintage International, 


\section{Crisensis

POE, Edgar Allan. The Philosophy of Composition. Poetry Foundation. Disponível em: https://www.poetryfoundation.org/articles/69390/the-philosophy-of-composition. Acesso em: 13, mar. 2021.

STOVALL, Floyd. The Women of Poe's Poems and Tales. In: Studies in English. Texas: University of Texas Press, 1925.

VALLE, Rude. As Time Goes By. Nova lorque: Brunswick Records, 1931. Disponível em: https://www.youtube.com/watch?v=_yTzjc056qM. Acesso em: 14, mar. 2021.

WOOLF, Virginia. Profissões para mulheres e outros artigos feministas. Porto Alegre: L\&PM, 2018. 